University of Wollongong

Research Online

Australian Institute for Innovative Materials -

Papers

Australian Institute for Innovative Materials

$1-1-2015$

Corrosion protection afforded by praseodymium conversion film on $\mathrm{Mg}$ alloy AZNd in simulated biological fluid studied by scanning electrochemical microscopy

Seyed S. Jamali

University of Wollongong, sjamali@uow.edu.au

Simon E. Moulton

University of Wollongong, smoulton@uow.edu.au

Dennis E. Tallman

North Dakota State University

Maria Forsyth

Monash University, Deakin University

Jan Weber

Boston Scientific

See next page for additional authors

Follow this and additional works at: https://ro.uow.edu.au/aiimpapers

Part of the Engineering Commons, and the Physical Sciences and Mathematics Commons

Research Online is the open access institutional repository for the University of Wollongong. For further information contact the UOW Library: research-pubs@uow.edu.au 


\title{
Corrosion protection afforded by praseodymium conversion film on Mg alloy AZNd in simulated biological fluid studied by scanning electrochemical microscopy
}

\begin{abstract}
Surface passivation of AZNd Mg alloy with $\operatorname{Pr}\left(\mathrm{NO}_{3}\right)_{3}$ is studied using scanning electrochemical microscopy (SECM) in surface generation/tip collection (SG/TC) and AC modes. Corrosion protection afforded by the Pr treatment and the degradation mechanism in a simulated biological environment was examined on a local scale and compared with non-treated AZNd. SG/TC mode results revealed a drastic decrease in $\mathrm{H} 2$ evolution due to the Pr treatment. Mapping the local insulating characteristics using ACSECM showed higher conductivity of the surface where $\mathrm{H}_{2}$ evolution was most favorable.
\end{abstract}

\section{Keywords}

scanning, studied, fluid, biological, simulated, corrosion, microscopy, protection, electrochemical, afforded, praseodymium, conversion, film, mg, alloy, aznd

\section{Disciplines}

Engineering | Physical Sciences and Mathematics

\section{Publication Details}

Jamali, S. S., Moulton, S. E., Tallman, D. E., Forsyth, M., Weber, J., Mirabedini, A. \& Wallace, G. G. (2015). Corrosion protection afforded by praseodymium conversion film on Mg alloy AZNd in simulated biological fluid studied by scanning electrochemical microscopy. Journal of Electroanalytical Chemistry, 739 211-217.

\section{Authors}

Seyed S. Jamali, Simon E. Moulton, Dennis E. Tallman, Maria Forsyth, Jan Weber, Azadehsadat Mirabedini, and Gordon G. Wallace 


\title{
Corrosion protection afforded by praseodymium conversion film on Mg alloy AZNd in simulated biological fluid studied by scanning electrochemical microscopy
}

Sina S. Jamali ${ }^{\mathrm{a}}$, Simon E. Moulton ${ }^{\mathrm{a} *}$, Dennis E. Tallman ${ }^{\mathrm{b}}$, Maria Forsyth ${ }^{\mathrm{c}}$, Jan Weber $^{\mathrm{d}}$, Azadeh Mirabedini ${ }^{\mathrm{a}}$, Gordon. G. Wallace ${ }^{\mathrm{a} *}$

${ }^{\mathrm{a}}$ ARC Centre of Excellence for Electromaterials Science, Intelligent Polymer Research Institute, AIIM Facility, Innovation Campus, University of Wollongong, NSW Australia

${ }^{\mathrm{b}}$ Department of Coatings and Polymeric Materials, North Dakota State University, Fargo, ND 58108-6050, United States.

'ARC Centre of Excellence for Electromaterials Science, Institute for Frontier Materials, Deakin University, Burwood Campus, Burwood, Victoria 3125, Australia.

${ }^{\mathrm{d}}$ Boston Scientific, G. Martinolaan 50, 6229 GS, Maastricht, Nederland.

Corresponding authors:

S.E. Moulton: smoulton@uow.edu.au

G.G. Wallace: gwallace@uow.edu.au

Tel: +61 24298 1443| Fax: +612 42213114

\begin{abstract}
Surface passivation of AZNd $\mathrm{Mg}$ alloy with $\operatorname{Pr}\left(\mathrm{NO}_{3}\right)_{3}$ is studied using scanning electrochemical microscopy (SECM) in surface generation/tip collection (SG/TC) and AC modes. Corrosion protection afforded by the Pr treatment and the degradation mechanism in a simulated biological environment was examined on a local scale and compared with nontreated AZNd. SG/TC mode results revealed a drastic decrease in $\mathrm{H}_{2}$ evolution due to the $\mathrm{Pr}$ treatment. Mapping the local insulating characteristics using AC-SECM showed higher conductivity of the surface where $\mathrm{H}_{2}$ evolution was most favorable.
\end{abstract}




\section{Introduction}

The rapid corrosion of magnesium and its tendency for localized corrosion in biological environments [1] are serious drawbacks that significantly limit its biomedical applications [2]. One effective method to overcome these issues is chemical modification of the magnesium surface. Chemically formed conversion coatings that occur via reaction of an active species (e.g. a rare earth element (REE)) can be more inert with respect to corrosion. Conversion coatings based on lanthanum (La), cerium (Ce) and praseodymium (Pr) has been shown to provide levels of corrosion protection to the underlying metal substrate and their protective properties have been studied for number of Mg alloys such as WE43 [3] AZ31 [4], AZ91, AM50 [5], AZ63 [6] and WE43 [7]. Majority of these studies have shown effective corrosion protection afforded by the REE conversion coating in the short term (e.g. under 24 hr) that tends to deteriorate as exposure time to corrosive environment increases. The corrosion inhibition mechanism of REE is often attributed to the deposition of an insoluble passive RE oxide/hydroxide film at cathodic domains [4,8], facilitated by the alkaline $\mathrm{pH}$ which arises from the reduction of water and/or oxygen [9]. The failure mechanism of these conversion coatings have been generally attributed to penetration of corrosive species (e.g. chloride) through the conversion coating towards the metal substrate. However, the role of coating inhomogeneities and localized defects in corrosion mechanism has not been fully understood due to the lack of studies with localized electrochemical methods.

The robust data collection modes of SECM present a unique localized electrochemical technique that combines capabilities of physically assessing insulating/conducting domains of a surface with highly sensitive chemical detection [10]. SECM in AC mode allows for localized detection of active/passive domains and defective areas of corrosion protective films on an active metal [11,12]. In generation/collection (G/C) mode of SECM, electrochemically 
oxidisable or reducible species produced at the substrate can be sensed via an electrochemical reaction at the SECM probe. Applying an oxidative potential at the SECM, flux of $\mathrm{H}_{2}$ evolution can be sensed and implemented to evaluate corrosion behaviour on Mg surface with a localized approach [13-15]. In comparison to other well-trusted corrosion measurement methods such as weight loss measurement and hydrogen collection $[16,17]$, SECM presents the unique capability of studying spontaneous corrosion phenomena while cumulative methods such as weight loss and hydrogen collection can only affords corrosion rate data after a certain period of immersion.

We investigate here a $\operatorname{Pr}$ surface treatment to impart corrosion protection to AZNd. In biomedical application, use of RE compounds should also be considered from the perspective of their potential cytotoxicity. Anti-carcinogenic properties of REs has been shown in number of studies [18-21], however some studies have also reported cytotoxic and hepatotoxic effects at high dose [22-25]. It has been shown that rare-earth alloying elements including Ce, $\mathrm{Nd}$, $\mathrm{Y}$, and $\mathrm{Yb}$ have no adverse effect on growth of living cells but they can induce inflammatory effects at high concentration [26]. In vitro studies of cytotoxicity of REs on primary human and mouse cells demonstrated highest relative cytotoxicity of La and Ce while good cell viability was achieved in presence of $\mathrm{Eu}, \mathrm{Nd}$ and $\operatorname{Pr}$ [27]. A recently advanced [13,15] electrochemical approach using SECM was used to evaluate $\mathrm{H}_{2}$ evolution as a measure of corrosion protection afforded by the surface treatment. Degradation of the Pr conversion layer on AZNd is also studied at a local scale using SECM in AC mode. The aim of this study is to help for better understanding of the degradation mechanism of a Pr conversion layer in a simulated biological environment. 


\section{Experimental}

\section{Material}

AZNd was supplied by Boston Scientific with the approximate composition of $\mathrm{Al} 7.26 \%$, Zn 0.59\%, Mn 0.10\%, Nd 0.66\% (all in $\mathrm{Wt} \%$ ) and the balance $\mathrm{Mg}$. XRF analysis measured the composition as $\mathrm{Al} 7.3 \%, \mathrm{Zn} 0.32 \%, \mathrm{Mn} 0.024 \%, \mathrm{Nd} 0.63 \%$ and the balance $\mathrm{Mg}$. The first composition detailed above is the actual quantities of elements used during the casting of the AZNd alloy. The XRF analysis was performed to investigate if contaminants entered the alloy composition during the casting process. The mismatch between the two compositions arises because the XRF results are collected at random locations on the surface of the alloy and do not match the average bulk composition. Further detail regarding the composition and corrosion properties of this alloy may be found in Ref. [28]. Simulated biological fluid (SBF) was prepared using analytical grade reagents consisting of $5.403 \mathrm{~g} / \mathrm{l} \mathrm{NaCl}, 0.504 \mathrm{~g} / \mathrm{l} \mathrm{NaHCO}$, $0.426 \mathrm{~g} / \mathrm{l} \mathrm{NaCO} 3,0.225 \mathrm{~g} / \mathrm{l} \mathrm{KCl}, 0.230 \mathrm{~g} / \mathrm{l} \mathrm{K} \mathrm{HPO}_{4} \cdot 3 \mathrm{H}_{2} \mathrm{O}, 0.311 \mathrm{~g} / \mathrm{l} \mathrm{MgCl}_{2} \cdot 6 \mathrm{H}_{2} \mathrm{O}, 0.8 \mathrm{~g} / \mathrm{l}$ $\mathrm{NaOH}, \quad 0.293 \mathrm{~g} / \mathrm{l} \quad \mathrm{CaCl}_{2}, \quad 0.072 \mathrm{~g} / \mathrm{l} \quad \mathrm{Na}_{2} \mathrm{SO}_{4}$ and 17.892 g/l HEPES (4-(2Hydroxyethyl)piperazine-1-ethanesulfonic acid - $\mathrm{C}_{8} \mathrm{H}_{18} \mathrm{~N}_{2} \mathrm{O}_{4} \mathrm{~S}$ ) as buffer agent [29]. The pH was adjusted to $7.40 \pm 0.05$ using $1 \mathrm{M} \mathrm{NaOH}$ (Sigma) solution. $\operatorname{Pr}\left(\mathrm{NO}_{3}\right)_{3} \cdot 6 \mathrm{H}_{2} \mathrm{O}$ and $\mathrm{NaOH}$ were analytical grade and purchased from Sigma-Aldrich Australia.

\section{Sample preparation}

All specimens (5mm x 5mm) were abraded successively using 600, 1200 and 2400 grit emery and ultrasonically cleaned in isopropanol before exposure to electrolyte. Specimens were then immersed in $0.2 \mathrm{M} \mathrm{NaOH}$ solution for 2 min. Specimens were then rinsed and conversion layers were formed by immersing the AZNd coupons in $0.2 \mathrm{M} \operatorname{Pr}\left(\mathrm{NO}_{3}\right)_{3}$ solution for $30 \mathrm{Sec}$. Specimens were then rinsed with DI water and dried with $\mathrm{N}_{2}$. This method produced a PrOx film with $700 \mathrm{~nm}$ to $1 \mu \mathrm{m}$ thickness confirmed by SEM analysis at the cross-section of 
samples (Figure 1). Pr treated samples were sputter coated with a $15 \mathrm{~nm}$ layer of Pt to minimise beam charging and heating effects and cast into epoxy resin in preparation for cross $\underline{\text { sectioning. Cross sections were analysed using back scatter SEM at an accelerating voltage of }}$ $15 \mathrm{kV}$ and a spot size setting of 14 . The brighter areas in Figure 1 correspond to the higher atomic numbers which is attributed to $\operatorname{Pr}$ conversion coating. It should be noted that preliminary studies were conducted to find the optimum concentration of $\operatorname{Pr}\left(\mathrm{NO}_{3}\right)_{3}$ in the conversion bath and immersion time as well as the pre-treatment of Mg coupons. It was found that low concentrations of $\operatorname{Pr}\left(\mathrm{NO}_{3}\right)_{3}$ tend to produce a discontinuous $\mathrm{PrOx}$ film while using high concentrations (e.g. $\left.>0.5 \mathrm{M} \operatorname{Pr}\left(\mathrm{NO}_{3}\right)_{3}\right)$ or long immersion time tend to severely attack the Mg substrate and produce a rough surface which was confirmed by optical profilometry method. Also it was found that surface pre-treatment by $0.2 \mathrm{M} \mathrm{NaOH}$ for 2 min resulted in a more uniform PrOx film and less corrosion attack during immersion in the conversion bath. The effect of the alkali pre-treatment in the $\mathrm{NaOH}$ solution has been extensively studied elsewhere [30-32] and shown to produce a dense and passive $\mathrm{Mg}(\mathrm{OH})_{2}$ layer. The role of $\underline{\mathrm{Mg}(\mathrm{OH})_{2}}$ passive layer in formation of a more uniform and less defective PrOx conversion coating is believed to occur due to controlling the rise of $\mathrm{pH}$ and localized attack at the surface of Mg. It has been shown that precipitation of intermediate compounds during the formation of rare earth oxide at the surface of $\mathrm{Mg}$ is facilitated by an increased $\mathrm{pH}[4,33,34]$. An unprotected Mg surface will undergo a severe localized attack in the presence of a strong $\underline{\text { oxidizing agent such as } \mathrm{NO}_{3}}-{ }^{-}$. It is believed that the alkali pre-treatment in a $\mathrm{NaOH}$ solution provides a moderately protective layer that controls the $\mathrm{pH}$ and minimizes the localized corrosion during formation of the conversion coating. 


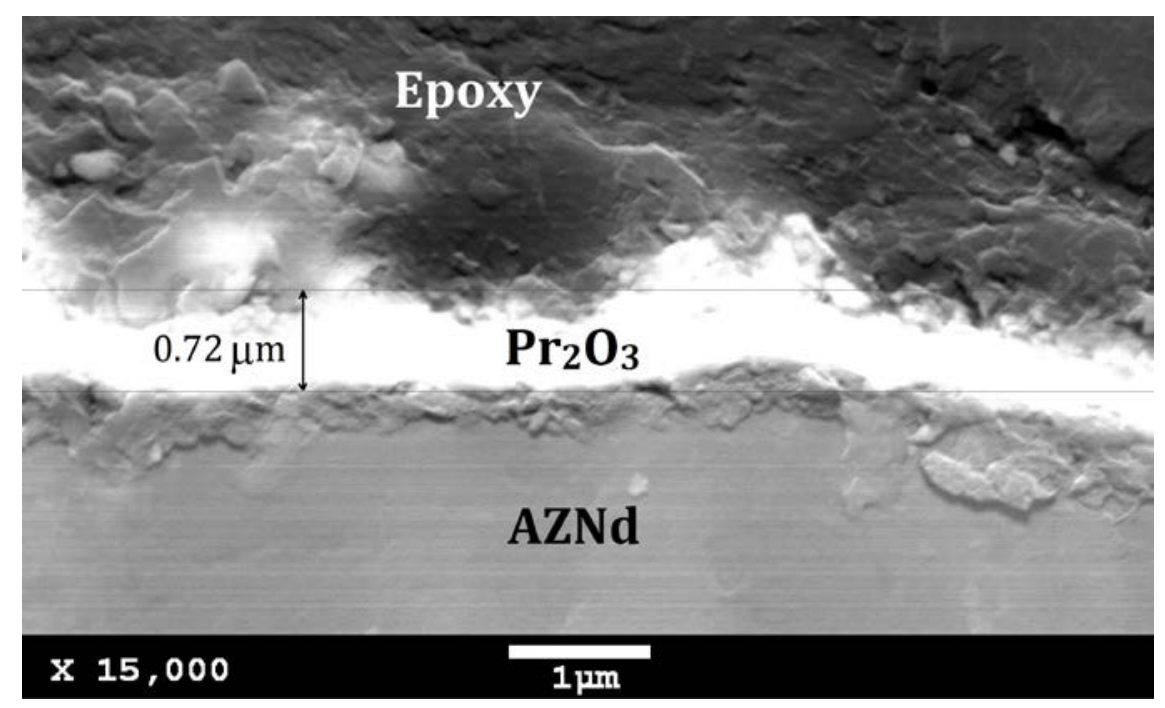

Figure 1 SEM micrograph (in back scatter mode) from cross-section of AZNd treated in

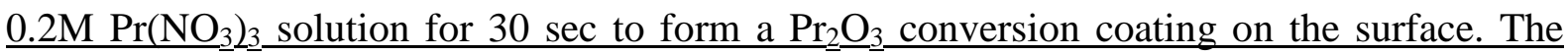
specimen was mounted in epoxy for the purpose of sample preparation.

\section{Methods}

Scanning electrochemical microscopy (SECM) was performed using $\mathrm{CH}$ instruments SECM

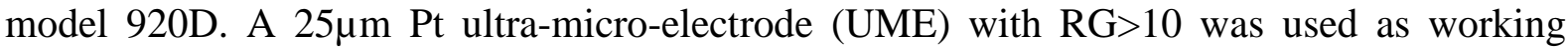
electrode. A Pt mesh and a standard $\mathrm{Ag} / \mathrm{AgCl}(3 \mathrm{M} \mathrm{KCl})$ served as reference and counter electrodes, respectively. An area of 1000x1000 $\mu \mathrm{m}$ was examined according to the experimental procedure described in reference [13]. A schematic representation of the SECM set-up and data collection principle used in this study is shown in Figure 2. The distance between tip and substrate was adjusted using a digital microscope, (MEIJI Techno model MS50). The substrate-tip distance was determined by bringing the SECM tip into contact with the sample; the tip was then raised using the $x-y-z$ positioning system of the SECM to the desired height above the sample. The tip was then moved in a lateral direction to the desired area of SECM analysis. In SG/TC mode, the SECM tip was biased at $0.0 \mathrm{~V}(\mathrm{Ag} / \mathrm{AgCl})$ for sensing $\mathrm{H}_{2}$ evolution via $\mathrm{H}_{2}$ electro-oxidation at the tip (Figure 2b) [13]. The stop time of UME at each given point of the surface for data collection in SG/TC mode was 0.02 second. 
AC mode imaging was performed in 100 -fold diluted SBF at a frequency of $1 \mathrm{kHz}$ with $\pm 200 \mathrm{mV}$ excitation amplitude to achieve maximum sensitivity towards resistive/capacitive properties of the surface film (Figure 2c). The stop time of UME at each given point of the surface for data collection in AC mode was around 0.5 second.
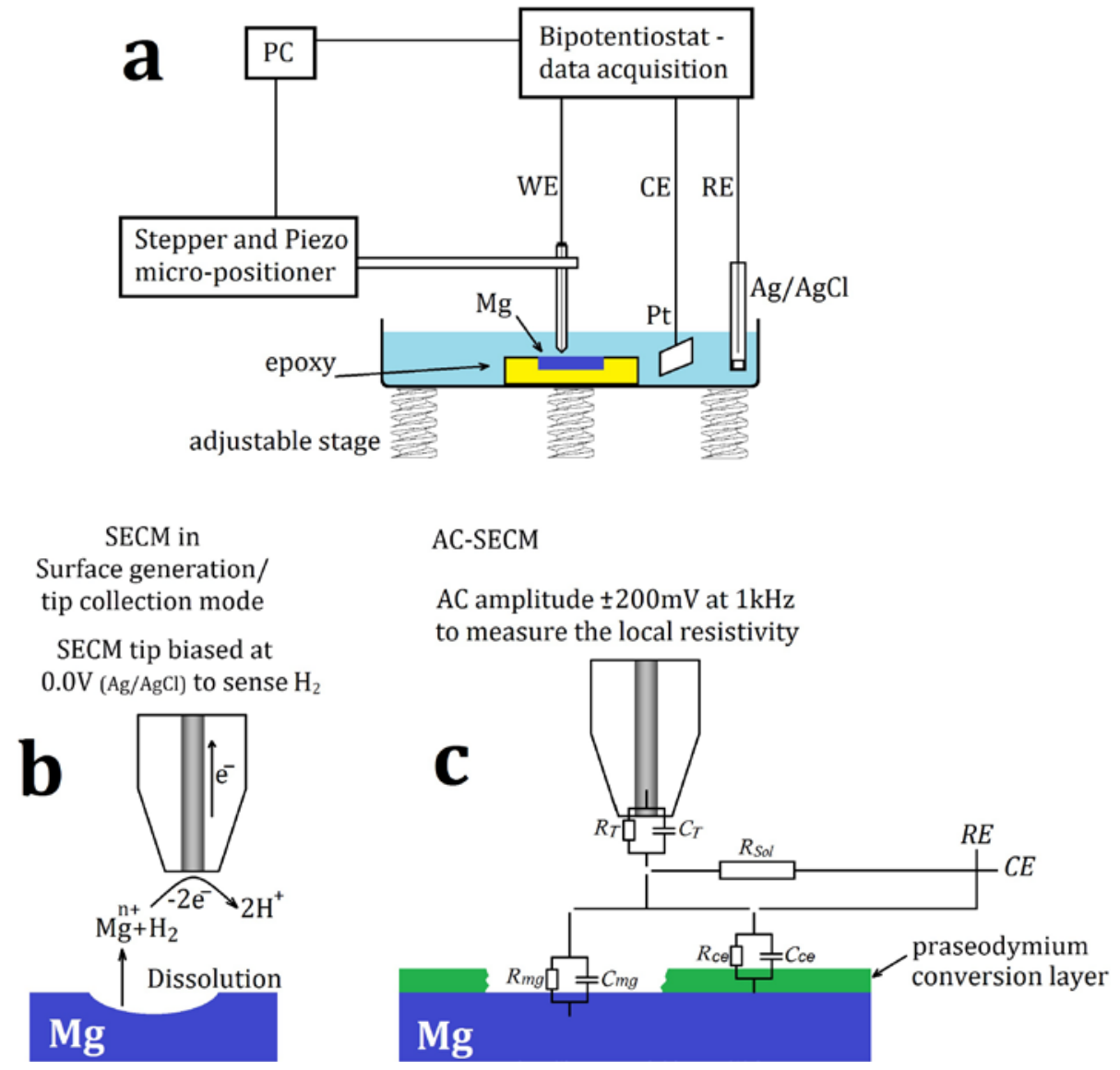

Figure 2 Schematic representation of (a) SECM set-up (b) $\mathrm{H}_{2}$ detection in SG/TC mode of SECM and (c) the electrical model of AC mode data acquisition at conducting and insulating regions of a Mg surface.

AC approach curves were generated by moving the UME tip from a distance of $75 \mu \mathrm{m}$ above the Mg substrate down to $<1 \mu \mathrm{m}$ from the substrate surface. Approach curves were generated at a number of frequencies from $100 \mathrm{kHz}$ to $1 \mathrm{kHz}$ in diluted SBF. The UME tip was held at 
OCP with an excitation AC signal amplitude of $200 \mathrm{mV}$. All experiments were performed at room temperature, (ca. $\left.22 \pm 2^{\circ} \mathrm{C}\right)$. The $\mathrm{Mg}$ substrate was at open circuit potential (OCP).

\section{Results and discussion}

SEM micrographs shown in Figure 3a and 3b illustrate the nano-porous structure of the Pr treated AZNd surface. EDX analysis (Figure 4 and Table 1) identified the chemical composition of surface layer as $\operatorname{Pr}_{2} \mathrm{O}_{3}$. The cracks in the $\mathrm{Pr}_{2} \mathrm{O}_{3}$ film shown in Figure 3a were not observed under optical microscope examination (Figure 3g) before the SEM analysis and therefore appearance of these cracks were attributed to the dehydration of the conversion film in vacuum chamber during SEM analysis. 

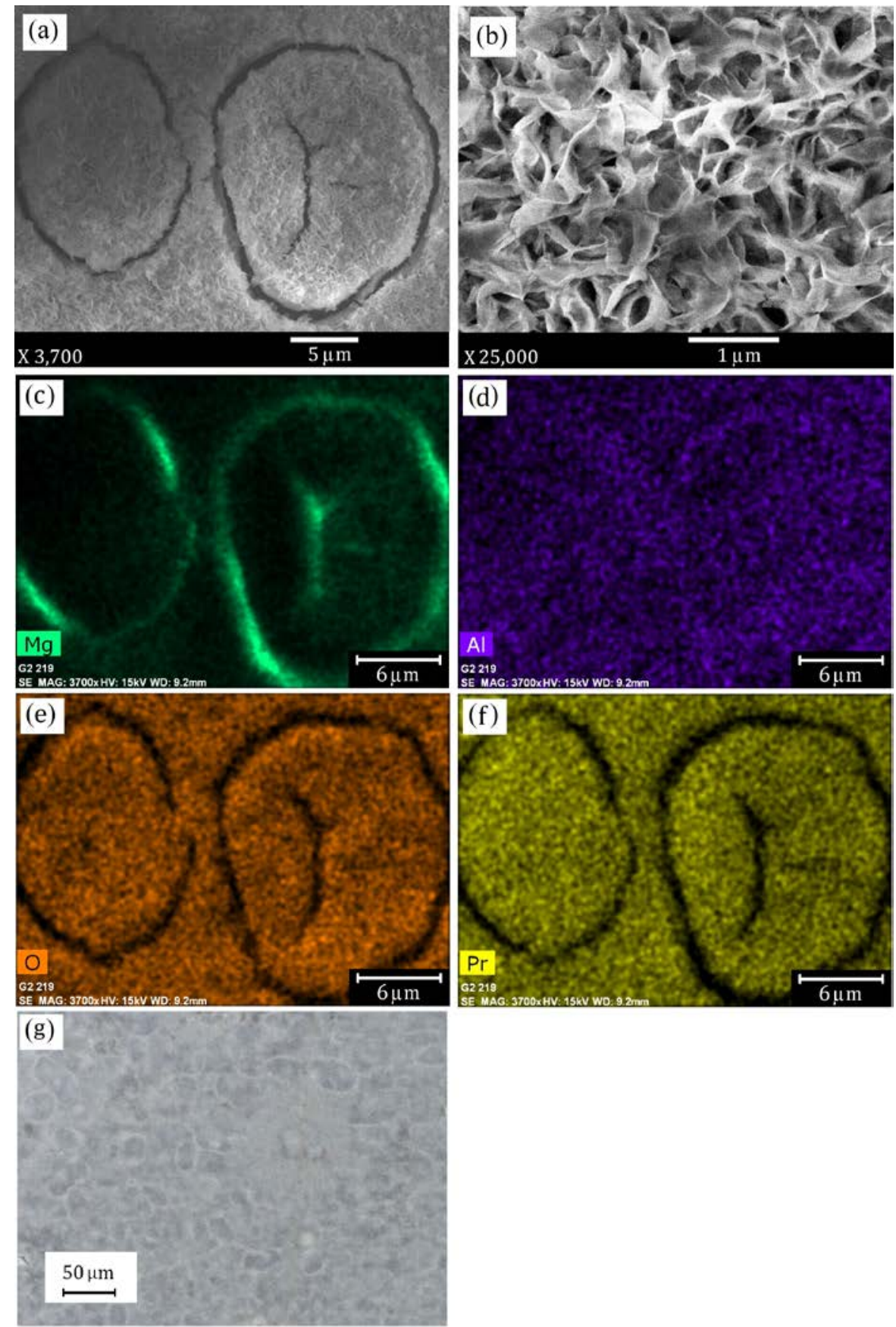

Figure 3 SEM micrographs (a and b) and elemental mapping (c-f) showing morphological

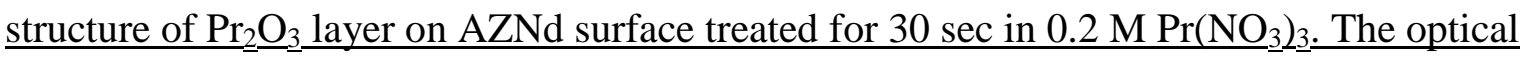
image (g) shows the Pr treated AZNd surface prior to undergoing SEM analysis. 


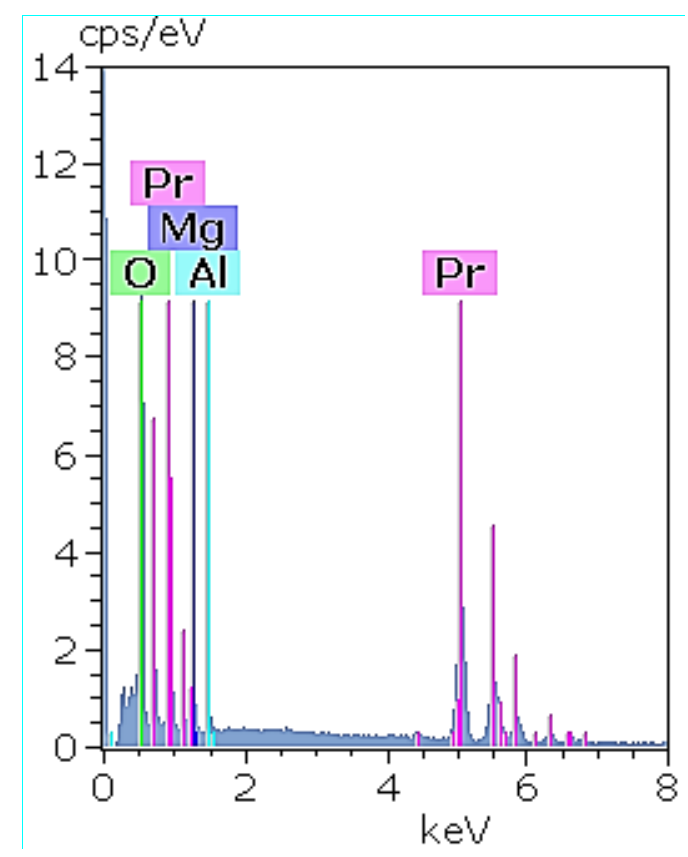

Figure 4 EDX elemental analysis of PrOx conversion layer on AZNd surface formed via immersion in $0.2 \mathrm{M} \operatorname{Pr}\left(\mathrm{NO}_{3}\right)_{3}$ solution for 30 Sec. Quantified data are presented in Table 1.

$\underline{\text { Table } 1 \text { Results of elemental and component analysis of Pr based conversion layer on AZNd }}$ surface confirming formation of $\mathrm{Pr}_{2} \underline{O}_{3}$ compound.

\begin{tabular}{cccc} 
Element & [norm. wt.\%] & Compound & [norm. wt.\%] \\
Oxygen & 16.82 & & 0.00 \\
\hline Magnesium & 4.06 & $\mathrm{MgO}$ & 6.73 \\
\hline Aluminium & 0.94 & $\mathrm{Al}_{2} \mathrm{O}_{3}$ & 1.77 \\
\hline Praseodymium & 78.18 & $\mathrm{Pr}_{2} \mathrm{O}_{3}$ & 91.50 \\
\hline
\end{tabular}

The insulating properties of the Pr conversion film on the surface of AZNd was examined using SECM in AC mode by producing AC approach curves and maps of local impedance before and after immersion in SBF. SECM imaging in AC mode consists of recording impedance magnitude and phase shift as a response to the excitation AC signal applied by the UME at a set frequency and excitation amplitude [13]. Corrosion resistance of the $\mathrm{Pr}$ conversion film is studied using SECM in the SG/TC mode for measuring $\mathrm{H}_{2}$ evolution from 
the $\mathrm{Mg}$ surface as a direct measure of corrosion rate. In SG/TC mode, $\mathrm{H}_{2}$ generation from corrosion of $\mathrm{Mg}$ (reaction 1) is sensed in an oxidation reaction (reactions 2 and 3) at the probe potential of $0.0 \mathrm{~V}(\mathrm{Ag} / \mathrm{AgCl})$. Comparison between $\mathrm{H}_{2}$ maps and impedance maps are made to further understand the protection mechanism.

$$
\begin{aligned}
& \mathrm{Mg}+2 \mathrm{H}_{2} \mathrm{O} \rightarrow \mathrm{Mg}^{2+}+2 \mathrm{OH}^{-}+\mathrm{H}_{2} \\
& \mathrm{H}_{2} \leftrightarrow 2 \mathrm{H}^{+}+2 \mathrm{e} \\
& \mathrm{H}_{2}+2 \mathrm{OH}^{-} \leftrightarrow 2 \mathrm{H}_{2} \mathrm{O}+2 \mathrm{e}
\end{aligned}
$$

Figure 5 shows the local impedance and $\mathrm{H}_{2}$ evolution maps for Pr treated (Figures 5a \& 5c) and non-treated (Figures 5b \& 5d) AZNd in dilute SBF. Comparison between Figure 5a and 5b (note different scale bars) reveals a more insulating characteristic of the Pr treated AZNd surface due to the formation of PrOx layer [4]. Figure 5c shows a significantly lower rate of $\mathrm{H}_{2}$ evolution (note the different scale bars) at the surface of the Pr treated AZNd, indicating a significantly lower rate of corrosion, correlating with the more resistive surface measured in Figure 5a, presumably due to the formation of a Pr rich conversion film. It is also clear that the domains on the surface which are less insulating result in the greatest $\mathrm{H}_{2}$ evolution. For example, on the non-protected surface localized currents as high as 9nA (Figure 5d) are recorded when the surface impedance is at its lowest value (Figure 5b). 


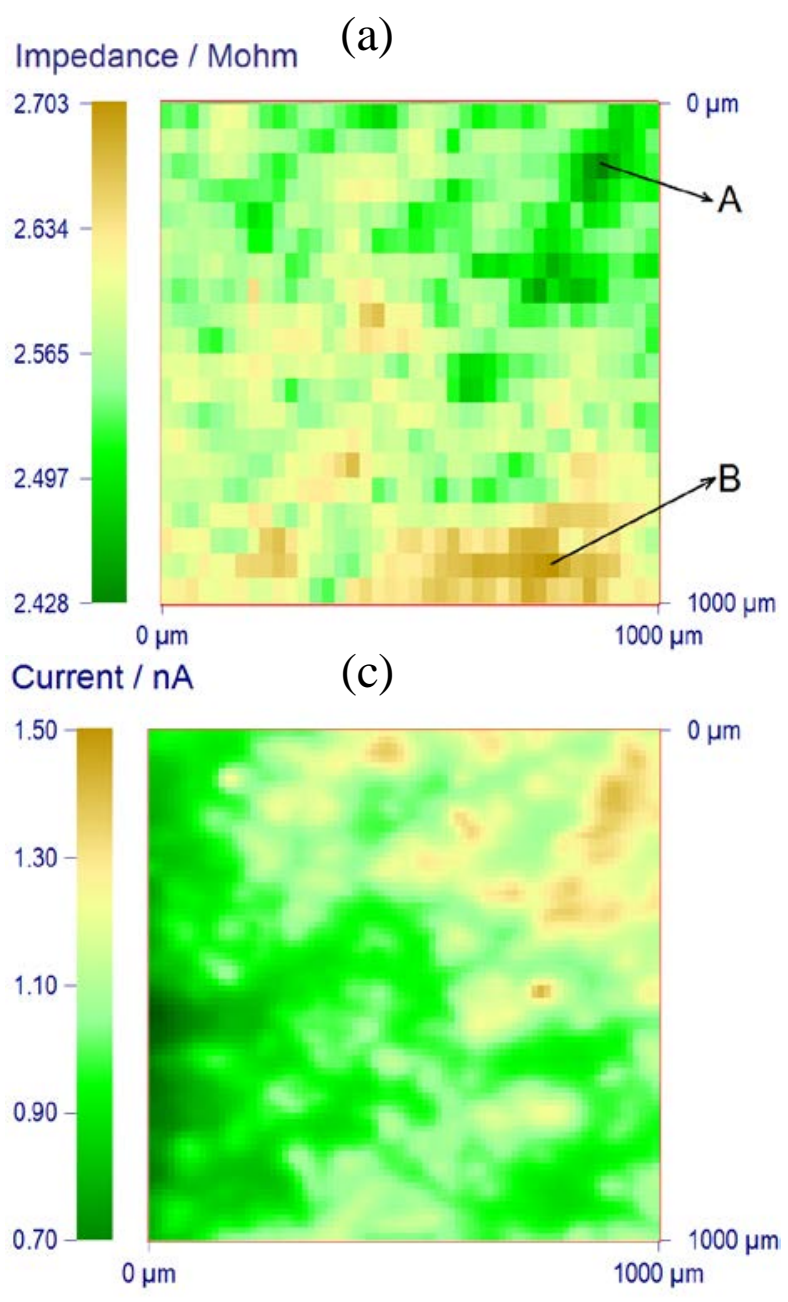

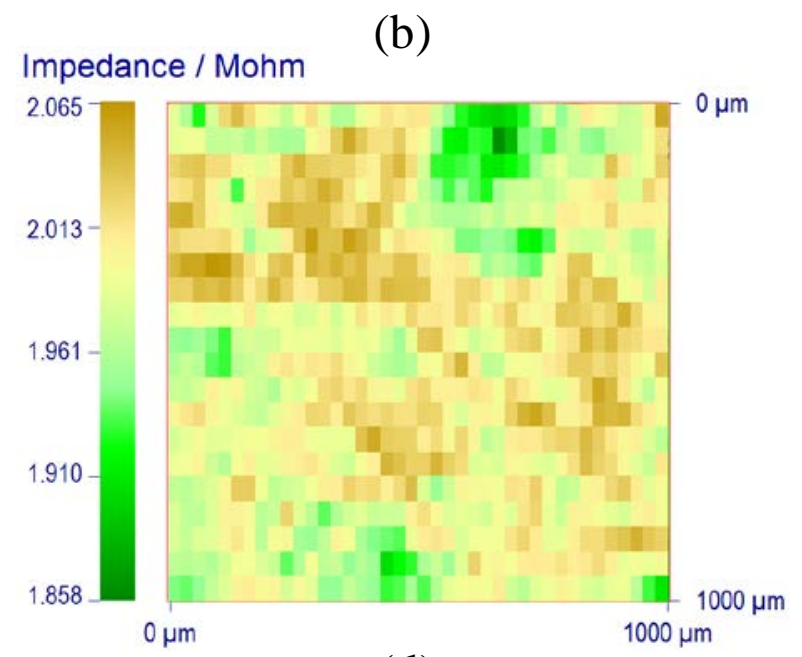

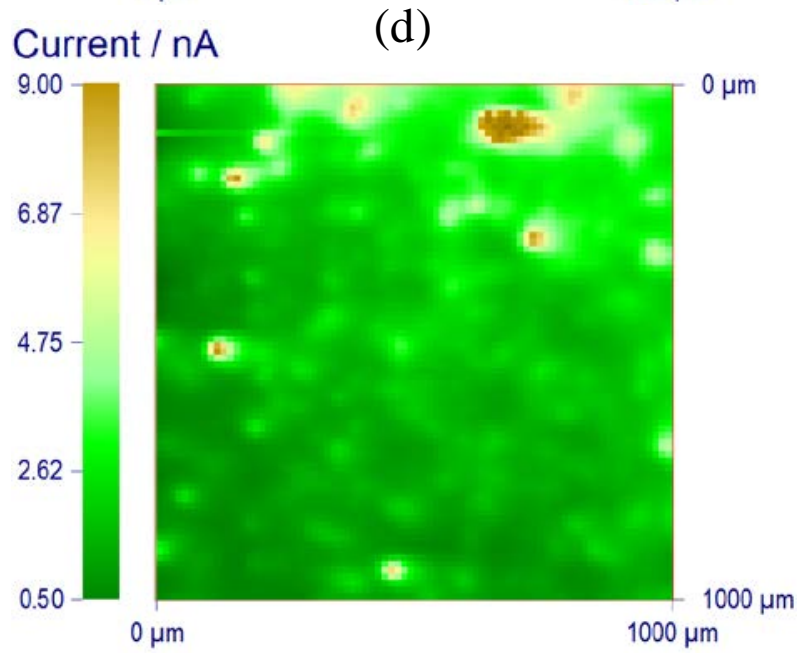

Figure 5 Local AC (impedance) (a and b) and SG/TC ( $\mathrm{H}_{2}$ evolution) (c and d) maps recorded on the surface of an AZNd sample, treated with $\operatorname{Pr}(\mathrm{a}$ and c) and untreated (b and d). AC (impedance) and SG/TC ( $\mathrm{H}_{2}$ evolution) measurements were made in dilute SBF using a $25 \mu \mathrm{m}$ Pt UME tip. AC scans were performed with $\pm 200 \mathrm{mV}$ AC excitation amplitude applied to the tip at $1 \mathrm{kHz}$ and $5 \mu \mathrm{m}$ tip-to-substrate distance. The SG/TC scans were performed using a Pt UME tip potential of $0.0 \mathrm{~V}$.

Two locations (marked as A and B in Figure 6a) on the surface of Pr treated AZNd were selected as representative domains for contrasting levels of insulating properties. AC approach curves were produced at A and B and are shown in Figures 6a and 6b, respectively. An AC approach curve on the surface of non-treated AZNd was also produced and is shown 
in Figure 7. Positive feedback (i.e., increasing normalised impedance as the UME tip approaches the AZNd surface) was observed for the treated surface (Figure 6a and 6b) at low frequencies (i.e. $\mathrm{f} \leq 42 \mathrm{kHz}$ ) while slight negative feedback (i.e., decreasing normalised impedance as the UME approaches the AZNd surface) was observed at high frequencies (i.e. f $>42 \mathrm{kHz})$.

The positive feedback observed at low frequencies was stronger at location B (Figure 6b) compared to A (Figure 6a), consistent with the higher impedance measured here. The slightly stronger negative feedback at higher frequencies at location A (Figure 6a) indicates higher ionic content of the electrolyte at this location resulting from the corrosion process. It should be noted that similar to conventional AC impedance spectroscopy, the impedance in ACSECM at sufficiently high frequencies is mainly dominated by the solution resistivity [35]. Figure 2c shows the alternative paths for AC signal which depends on the frequency domain. More details on the elements playing a part in defining the AC impedance at each frequency domain is given in Ref. [35]. This observation is also consistent with results of a previous study [13] that showed correlation between areas of higher conductivity, higher $\mathrm{H}_{2}$ evolution and greater ionic $\left(\mathrm{OH}^{-}\right)$content.

AC approach curves at the surface of the non-treated AZNd (Figure 7) show significantly weaker positive feedback at low frequencies, again consistent with lower impedance values measured for this surface, while stronger negative feedback at high frequencies indicates generation and accumulation of ionic species at the surface, most likely due to increased corrosion products from the AZNd surface. 

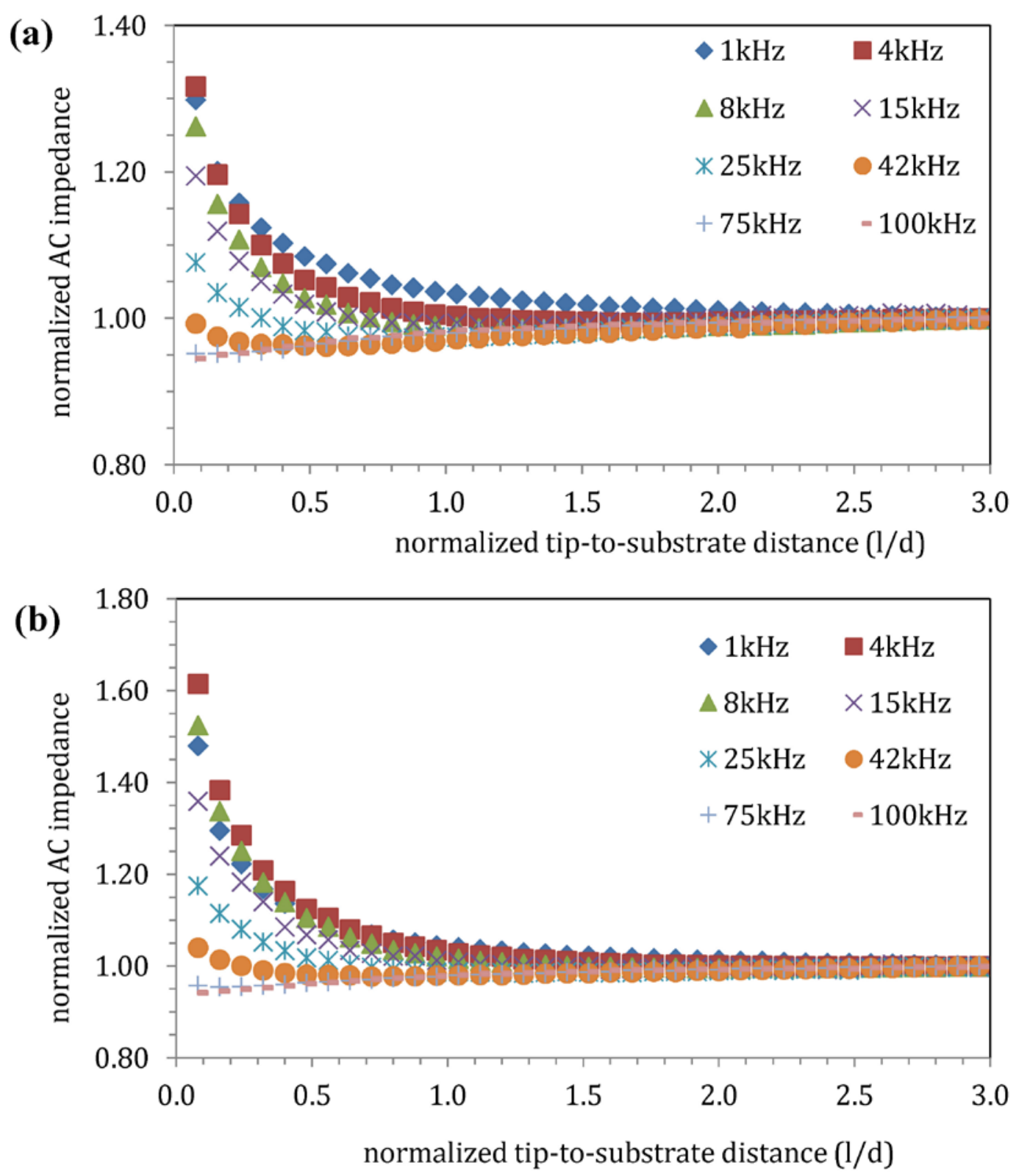

Figure 6 AC (impedance) approach curves on Pr treated AZNd recorded in dilute SBF. (a) is associated with location A in Figure 5a and (b) is from location B in Figure 5a. Approach curves were obtained using a Pt UME (25 $\mu$ m diameter tip) SECM probe with applied AC excitation amplitude of $\pm 200 \mathrm{mV}$ starting from a tip-to-substrate distance of $75 \mu \mathrm{m}$. 


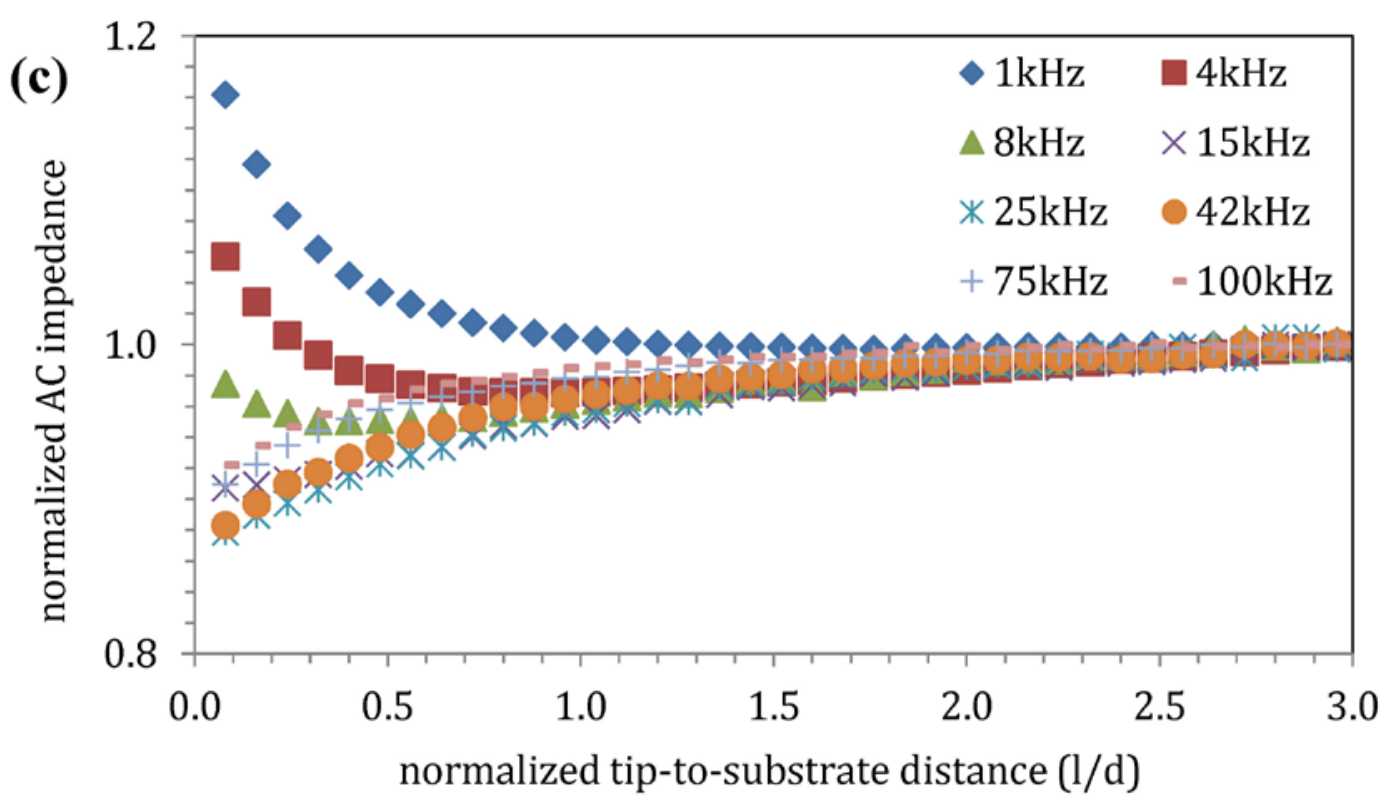

Figure 7 AC (impedance) approach curves on AZNd recorded in dilute SBF obtained using a Pt UME (25 $\mu$ m diameter tip) SECM probe with applied AC excitation amplitude of $\pm 200 \mathrm{mV}$ starting from a tip-to-substrate distance of $75 \mu \mathrm{m}$.

Results of the local impedance and $\mathrm{H}_{2}$ evolution for the Pr treated and non-treated samples after 2hrs immersion in SBF are shown in Figure 8. The $\mathrm{H}_{2}$ evolution maps were acquired in non-dilute SBF in order to examine the performance of the Pr conversion layer in a highly corrosive medium. The horizontal lines observed in Figures 8c \& 8d are believed to be due to excessive $\mathrm{H}_{2}$ evolution in non-diluted $\mathrm{SBF}$ and small $\mathrm{H}_{2}$ pockets occasionally attaching to the UME tip. It is noteworthy to mention that these lines are consistent with the horizontal direction of scan and that these lines were not observed in the images acquired in dilute SBF. The same regions of the AZNd samples displayed in Figure 5 are also displayed in Figure 8. Comparisons of Figures 5a and 5b with Figures 8a and 8b illustrate that the major domains of low impedance (e.g. top right corner in Figure 5a and 5b) remain at the same place after $2 \mathrm{~h}$ of exposure to highly corrosive SBF media. However, other domains which showed high impedance initially show less insulating characteristics after 2 hours immersion in this more aggressive medium. It has been suggested that the porous structure of PrOx films allows for 
penetration of corrosive ions [3] such as chloride and leads to under-film corrosion of $\mathrm{Mg}$. Nevertheless, the hydrogen evolution reaction still appears supressed on the treated AZNd with the untreated sample when the absolute currents are noted in Figures 8c and 8d, indicating an effective corrosion protection afforded by the Pr treatment surface probably due to formation of a Pr conversion layer.
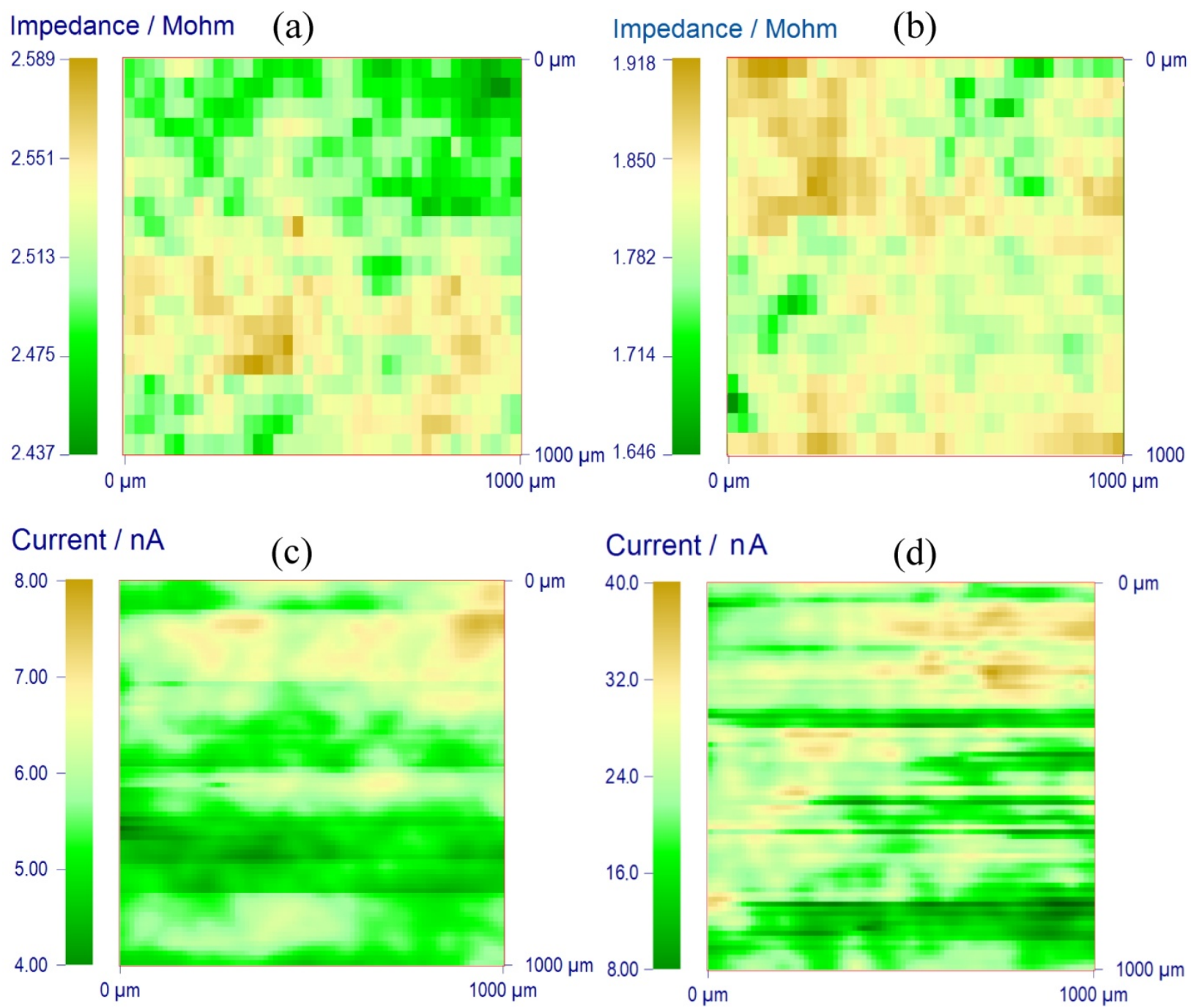

Figure 8 Local impedance ( $\mathrm{a}$ and $\mathrm{b}$ ) and $\mathrm{H}_{2}$ evolution (c and d) obtained on the surface of a AZNd sample, treated (a and c) with Pr and untreated (b and d) after immersion in SBF for 2hrs. SG/TC ( $\mathrm{H}_{2}$ evolution) measurements were performed in non-dilute SBF and then the samples were transferred to dilute SBF to perform the AC mode measurement. AC maps were 
obtained with $\pm 200 \mathrm{mV}$ AC excitation amplitude applied to the tip at $1 \mathrm{kHz}$ and $5 \mu \mathrm{m}$ tip-tosubstrate distance. The SG/TC maps were obtained using a Pt UME tip potential of 0.0V.

\section{Conclusion}

AC-SECM results showed that Pr treatment using nitrate salt solution results in formation of an inconsistent PrOx conversion layer on the AZNd Mg alloy with a variation of insulating properties across the surface. Sensing $\mathrm{H}_{2}$ evolution by means of SECM in SG/TC mode was used as a method of examining the corrosion behavior of $\mathrm{Mg}$ and obtaining comparative measures of corrosion rate between a non-treated and a Pr treated Mg surface. It was shown that corrosion resistance of AZNd during a short term immersion in SBF is improved due to Pr treatment. However, it was observed that some insulating domains of the PrOx film broke down after $2 \mathrm{~h}$ immersion and showed higher $\mathrm{H}_{2}$ evolution activity.

\section{Acknowledgments}

The authors thank the Australian Research Council (ARC) for continuing financial support. GGW and MF thank the ARC for their Laureate Fellowships and SEM thanks the ARC for his QEII Fellowship.

\section{References}

[1] Y. Xin, T. Hu, P.K. Chu, In vitro studies of biomedical magnesium alloys in a simulated physiological environment: a review, Acta Biomater. 7 (2011) 1452-9. doi:10.1016/j.actbio.2010.12.004.

[2] J.A. Grogan, B.J. O’Brien, S.B. Leen, P.E. McHugh, A corrosion model for bioabsorbable metallic stents., Acta Biomater. 7 (2011) 3523-33. doi:10.1016/j.actbio.2011.05.032.

[3] A. Rudd, C. Breslin, F. Mansfeld, The corrosion protection afforded by rare earth conversion coatings applied to magnesium, Corros. Sci. 42 (2000) 275-288. 
[4] M.F. Montemor, A.M. Simões, M.J. Carmezim, Characterization of rare-earth conversion films formed on the AZ31 magnesium alloy and its relation with corrosion protection, Appl. Surf. Sci. 253 (2007) 6922-6931. doi:10.1016/j.apsusc.2007.02.019.

[5] K. Brunelli, M. Dabalà, I. Calliari, M. Magrini, Effect of $\mathrm{HCl}$ pre-treatment on corrosion resistance of cerium-based conversion coatings on magnesium and magnesium alloys, Corros. Sci. 47 (2005) 989-1000. doi:10.1016/j.corsci.2004.06.016.

[6] M. Dabalà, K. Brunelli, E. Napolitani, M. Magrini, Cerium-based chemical conversion coating on AZ63 magnesium alloy, Surf. Coat. Technol. 172 (2003) 227-232. doi:10.1016/S0257-8972(03)00336-0.

[7] F. Zucchi, V. Grassi, A. Frignani, C. Monticelli, G. Trabanelli, Influence of a silane treatment on the corrosion resistance of a WE43 magnesium alloy, Surf. Coat. Technol. 200 (2006) 4136-4143. doi:10.1016/j.surfcoat.2005.02.073.

[8] N.C. Rosero-navarro, M. Curioni, R. Bingham, A. Durán, M. Aparicio, R.A. Cottis, et al., Electrochemical techniques for practical evaluation of corrosion inhibitor effectiveness . Performance of cerium nitrate as corrosion inhibitor for AA2024T3 alloy, Corros. Sci. 52 (2010) 3356-3366. doi:10.1016/j.corsci.2010.06.012.

[9] S. Joshi, E. a. Kulp, W.G. Fahrenholtz, M.J. O’Keefe, Dissolution of cerium from cerium-based conversion coatings on $\mathrm{Al} 7075-\mathrm{T} 6$ in $0.1 \mathrm{M} \mathrm{NaCl}$ solutions, Corros. Sci. 60 (2012) 290-295. doi:10.1016/j.corsci.2012.03.023.

[10] M.B. Jensen, D.E. Tallman, Application of SECM in corrosion reseach, in: A.J. Bard, M. V Mirkin (Eds.), Scanning Electrochem. Microsc., 2nd editio, Taylor and Francis/CRC Press, NY, USA, 2012: pp. 451-488.

[11] M. Pähler, J.J.J. Santana, W. Schuhmann, R.M. Souto, Application of AC-SECM in corrosion science: local visualisation of inhibitor films on active metals for corrosion protection., Chem. Eur. J. 17 (2011) 905-11. doi:10.1002/chem.201000689.

[12] B.B. Katemann, C.G. Inchauspe, P. a Castro, A. Schulte, E.J. Calvo, W. Schuhmann, Precursor sites for localised corrosion on lacquered tinplates visualised by means of alternating current scanning electrochemical microscopy, Electrochim. Acta. 48 (2003) 1115-1121. doi:10.1016/S0013-4686(02)00822-8.

[13] S.S. Jamali, S.E. Moulton, D.E. Tallman, M. Forsyth, J. Weber, G.G. Wallace, Applications of scanning electrochemical microscopy (SECM) for local characterization of AZ31 surface during corrosion in a buffered media, Corros. Sci. 86 (2014) 93-100. doi:10.1016/j.corsci.2014.04.035.

[14] U.M. Tefashe, M.E. Snowden, P. Dauphin, M. Danaie, G.A. Botton, J. Mauzeroll, Local Flux of Hydrogen from Magnesium Alloy Corrosion Investigated by Scanning Electrochemical Microscopy, J. Electroanal. Chem. 720-721 (2014) 121-127. doi:10.1016/j.jelechem.2014.03.002.

[15] S.S. Jamali, S.E. Moulton, D.E. Tallman, M. Forsyth, J. Weber, G.G. Wallace, Evaluating the corrosion behaviour of Magnesium alloy in simulated biological fluid 
by using SECM to detect hydrogen evolution, Electrochim. Acta. (2014).

doi:10.1016/j.electacta.2014.11.012.

[16] G.-L. Song, A. Atrens, Understanding magnesium corrosion - a framework for improved alloy performance, Adv. Eng. Mater. 5 (2003) 837-858.

[17] G. Song, A. Atrens, D. St. John, An hydrogen evolution method for the estimation of the corrosion rate of magnesium alloys, in: Magnes. Technol. 2001 Symp., Minerals, Metals \& Materials Society, New Orleans, LA, 2001: pp. 255-262.

[18] Y. Dai, J. Li, L. Yu, G. Dai, A. Hu, Effects of rare earth compounds on growth and apoptosis of leukemic cell lines, Vitr. Cell. Dev. Biol. Anim. 38 (2002) 373-5.

[19] Y. Ji, B. Xiao, Z. Wang, M. Cui, Y. Lu, The suppression effect of light rare earth elements on proliferation of two cancer cell lines., Biomed Env. Sci. 13 (2000) 28792.

[20] I. Kostova, G. Momekov, P. Stancheva, New samarium (III), gadolinium (III), and dysprosium (III) complexes of coumarin-3-carboxylic acid as antiproliferative agents, Met. Based Drugs. (2007) 15925.

[21] D. Magda, R. Miller, Motexafin gadolinium: a novel redox active drug for cancer therapy, Semin. Cancer Biol. 16 (2006) 466-76.

[22] T. Haley, K. Raymond, N. Komesu, H. Upham, Toxicological and pharmacological effects of gadolinium and samarium chlorides, Br. J. Pharmacol. Chemother. 17 (1961) 526-32.

[23] D. Bruce, B. Hietbrink, K. DuBois, The acute mammalian toxicity of rare earth nitrates and oxides, Toxicol. Appl. Pharm. 5 (1963) 750-9.

[24] Y. Nakamura, Y. Tsumura, Y. Tonogai, Y. Shibata, Y. Ito, Differences in behavior among the chlorides of seven rare earth elements administered intravenously to rats, Fund. Appl. Toxicol. 37 (1997) 106-16.

[25] W. Yang, P. Zhang, J. Liu, Y. Xue, Effect of long-term intake of Y 3+ in drinking water on gene expression in brains of rats, J. Rare Earth. 24 (2006) 369-73.

[26] A. Drynda, N. Deinet, N. Braun, M. Peuster, Rare earth metals used in biodegradable magnesium-based stents do not interfere with proliferation of smooth muscle cells but do induce the upregulation of inflammatory genes., J. Biomed. Mater. Res. A. 91 (2009) 360-9. doi:10.1002/jbm.a.32235.

[27] F. Feyerabend, J. Fischer, J. Holtz, F. Witte, R. Willumeit, H. Drücker, et al., Evaluation of short-term effects of rare earth and other elements used in magnesium alloys on primary cells and cell lines., Acta Biomater. 6 (2010) 1834-42. doi:10.1016/j.actbio.2009.09.024.

[28] J. Weber, A. Flanagan, T. Scheuermann, US patent: Bioerodible Magnesium Alloy Containing Endoprostheses, US20120059455 A1, 2012. 
[29] X. Liu, Z. Yue, T. Romeo, J. Weber, T. Scheuermann, S.E. Moulton, et al., Biofunctionalized anti-corrosive silane coatings for magnesium alloys., Acta Biomater. 9 (2013) 8671-7. doi:10.1016/j.actbio.2012.12.025.

[30] C. Lorenz, J.G. Brunner, P. Kollmannsberger, L. Jaafar, B. Fabry, S. Virtanen, Effect of surface pre-treatments on biocompatibility of magnesium., Acta Biomater. 5 (2009) 2783-9. doi:10.1016/j.actbio.2009.04.018.

[31] Y. Zhu, G. Wu, Y.-H. Zhang, Q. Zhao, Growth and characterization of $\mathrm{Mg}(\mathrm{OH}) 2$ film on magnesium alloy AZ31, Appl. Surf. Sci. 257 (2011) 6129-6137. doi:10.1016/j.apsusc.2011.02.017.

[32] P. Chakraborty Banerjee, R.K. Singh Raman, Electrochemical impedance spectroscopic investigation of the role of alkaline pre-treatment in corrosion resistance of a silane coating on magnesium alloy, ZE41, Electrochim. Acta. 56 (2011) 37903798. doi:10.1016/j.electacta.2011.02.050.

[33] F. Li, R. Newman, G. Thompson, In situ atomic force microscopy studies of electrodeposition mechanism of cerium oxide films: nucleation and growth out of a gel mass precursor, Electrochim. Acta. 42 (1997) 2455-2464.

[34] C.S. Lin, S.K. Fang, Formation of Cerium Conversion Coatings on AZ31 Magnesium Alloys, J. Electrochem. Soc. 152 (2005) B54. doi:10.1149/1.1845371.

[35] K. Eckhard, W. Schuhmann, Alternating current techniques in scanning electrochemical microscopy (AC-SECM), Analyst. 133 (2008) 1486-97. doi:10.1039/b806721j. 